Check for updates

Cite this: RSC Adv., 2017, 7, 47840

Received 15th August 2017

Accepted 27th September 2017

DOI: $10.1039 / c 7 r a 09002 a$

rsc.li/rsc-advances

\section{Photoluminescent carbon dots derived from sugarcane molasses: synthesis, properties, and applications $\uparrow$}

\author{
Gang Huang, (D) ad Xing Chen, ${ }^{\text {b }}$ Cong Wang, ${ }^{c}$ Hongyu Zheng, ${ }^{\mathrm{c}}$ Zuqiang Huang, ${ }^{\text {*d }}$ \\ Dong Chen ${ }^{\star a}$ and Haihui Xie ${ }^{e}$
}

Carbon dots ( $\mathrm{C}$-dots) were prepared through a simple, environmentally friendly hydrothermal method, with the use of sugarcane molasses derived from industrial waste as the carbon source. The C-dots were characterized via X-ray photoelectron spectroscopy (XPS), Fourier transform infrared (FT-IR) spectroscopy, nuclear magnetic resonance (NMR), high-resolution transmission electron microscopy (HRTEM), thermogravimetric analysis (TGA), and UV-vis absorption spectroscopy, as well as fluorescence spectroscopy. The C-dots exhibited a spherical shape with a diameter of around $1.9 \mathrm{~nm}$, and emitted blue photoluminescence with a quantum yield of approximately $5.8 \%$. The effects of $\mathrm{pH}$, sodium chloride $(\mathrm{NaCl})$, amino acids and metal ions on the photoluminescence were further investigated. Not only was the biocompatibility of the $\mathrm{C}$-dots assessed in vitro and in vivo, but also their bioimaging ability was observed in MCF-7 cells. The effect of C-dots on secondary structure of bovine serum albumin (BSA) was investigated. Additionally, it was found that the fluorescence intensity of the C-dots decreased after addition of $\mathrm{Fe}^{3+}$ or sunset yellow. Furthermore, the underlying mechanism of fluorescence quenching was proposed in the $\mathrm{C}$-dots/sunset yellow system.

\section{Introduction}

Carbon dots (C-dots), consisting of $\mathrm{sp}^{2} / \mathrm{sp}^{3}$ hybridized carbon atoms, are quasi-spherical nanomaterials with a diameter of less than $10 \mathrm{~nm} .{ }^{1} \mathrm{C}$-dots have attracted enormous attention in a host of applications such as drug delivery, ${ }^{2}$ bioimaging, ${ }^{3}$ and biosensors $^{4}$ due to their ease of preparation, excellent water solubility, outstanding fluorescence properties, low toxicity, fine resistance to photobleaching and facile surface functionalization. In terms of carbon sources, diverse materials are chosen owing to the ease of their obtainment, e.g. vegetables, ${ }^{5}$ fruits, ${ }^{6}$ polymers, ${ }^{7}$ and even wastes. ${ }^{8}$

Sugarcane molasses is derived from industrial waste after a series of further purification processes for sugar production, and has a total sugar content of approximately $50 \%$ including sucrose, glucose and fructose. Owing to its high sugar content

${ }^{a}$ State Key Laboratory of Non-food Biomass and Enzyme Technology, Guangxi Academy of Sciences, Nanning, China. E-mail: 13878190484@163.com

${ }^{b}$ School of Public Health, Guangxi Medical University, Nanning, China. E-mail: chenx63@163.com

'Medical Examination Center, The People's Hospital of Guangxi Zhuang Autonomous Region, Nanning, China

${ }^{d}$ School of Chemistry and Chemical Engineering, Guangxi University, Nanning, China. E-mail: huangzq@gxu.edu.cn

${ }^{e}$ Medical Examination Center, The Eighth People's Hospital of Nanning, China

$\dagger$ Electronic supplementary information (ESI) available. See DOI: 10.1039/c7ra09002a and low-price, sugarcane molasses has been utilized not only as animal feed, ${ }^{9}$ but also as biomass energy in the field of microbial fermentation. ${ }^{10}$ Besides, sugarcane molasses has also been investigated as an antioxidant agent, ${ }^{9}$ additive ${ }^{11}$ and fertilizer. ${ }^{12}$ Recently, sugarcane molasses has been separated through centrifugation to obtain C-dots that may be exploited as biosensors for riboflavin and tetracycline. ${ }^{13}$ However, the chemical structure and fluorescence properties of C-dots derived from sugarcane molasses are still unclear. The natural environment and the sugar manufacturing industry are still incurring heavy burdens and facing grand challenges due to yielding several million tons of sugarcane molasses every year. Hence, it is imperative to encourage exploration of the application of sugarcane molasses as a novel raw material for carbon dots.

Sunset yellow, which has an azo $(-\mathrm{N}=\mathrm{N}-)$ functional group and aromatic ring structure, is a synthetic organic food dye that is utilized in food daily due to its low price and good quality. ${ }^{14}$ Excessive intake of sunset yellow by human beings may cause underlying diseases. ${ }^{15}$ Consequently, it is important and urgent for human public health to sense sunset yellow. Although diverse methods have been developed, they are time-consuming or expensive, such as high-performance liquid chromatography (HPLC),${ }^{16}$ electroanalytical techniques ${ }^{14}$ spectrophotometry ${ }^{17}$ and enzyme-linked immunosorbent assays. ${ }^{18}$

To facilitate the applications of sugarcane molasses, C-dots, using sugarcane molasses as the carbon source, were prepared 
though thermal treatment and then characterized by X-ray photoelectron spectroscopy (XPS), Fourier transform infrared spectroscopy (FT-IR), nuclear magnetic resonance (NMR) and thermogravimetric analysis (TGA) in this work. The fluorescence property of the C-dots was assessed in various environments involving varying $\mathrm{pHs}$, sodium chloride $(\mathrm{NaCl})$, amino acids and metal ions. The stability and antioxidant capacity were investigated in detail. The morphology of the C-dots was observed and the cytotoxicity was demonstrated in vitro and in vivo. The C-dots were exploited in living cell imaging and detection of $\mathrm{Fe}^{3+}$ and sunset yellow. Moreover, the mechanism of fluorescence quenching was further investigated by virtue of the decreased fluorescence of the C-dots after addition of sunset yellow.

\section{Materials and methods}

\section{Materials}

Sugarcane molasses was obtained from Guangxi Haiying Alcohol Co., Ltd. NaCl, $\mathrm{CaCl}_{2}, \mathrm{KCl}, \mathrm{MgCl}_{2}, \mathrm{CuSO}_{4} \cdot 5 \mathrm{H}_{2} \mathrm{O}$, $\mathrm{MnCl}_{2} \cdot 4 \mathrm{H}_{2} \mathrm{O}, \mathrm{Cr}\left(\mathrm{NO}_{3}\right)_{3} \cdot 9 \mathrm{H}_{2} \mathrm{O}, \mathrm{FeSO}_{4} \cdot 7 \mathrm{H}_{2} \mathrm{O}, \mathrm{La}\left(\mathrm{NO}_{3}\right)_{3} \cdot 6 \mathrm{H}_{2} \mathrm{O}$, $\mathrm{Cd}\left(\mathrm{CH}_{3} \mathrm{COO}\right)_{2} \cdot 2 \mathrm{H}_{2} \mathrm{O}$, and 1,1-diphenyl-2-picrylhydrazyl (DPPH) were purchased from Sigma-Aldrich. All of the other reagents were used as received unless otherwise stated. A breast cancer cell line (MCF-7) was purchased from the Cell Bank of Chinese Academy of Sciences (Shanghai, China). BALB/C nude mice were obtained from the Beijing Vital River Laboratory Animal Technology Co. Ltd. Human red blood cells were obtained from the People's Hospital of Guangxi Zhuang Autonomous Region.

\section{Preparation of C-dots}

$5.0 \mathrm{~g}$ of sugarcane molasses was added into an autoclave and heated at $250{ }^{\circ} \mathrm{C}$ for $12 \mathrm{~h}$. After cooling to room temperature, $10 \mathrm{~mL}$ of deionized water was added to the mixture, and then filtered through a $0.22 \mu \mathrm{m}$ membrane to remove large particles. The filtrate was dispersed in $250 \mathrm{~mL}$ of anhydrous ethanol. The mixture was centrifuged at $6000 \mathrm{rpm}$ for $10 \mathrm{~min}$ to remove brown particles. The supernatant solution was evaporated under a reduced pressure. The final product was dissolved in $5 \mathrm{~mL}$ of deionized water and lyophilized for $72 \mathrm{~h}$ (yield: $0.41 \mathrm{~g}$, $8.2 \%)$.

\section{Characterization of C-dots}

XPS measurements were carried out on a Kratos Axis Ultra Dld. NMR spectra were recorded on an Agilent Technologies 800/54 premium. UV-vis absorption and fluorescence spectra were measured by a Beckman Coulter DU800 and a Hitachi F-7000. The fluorescence lifetime and quantum yield were measured using a Hamamatsu Compact Fluorescence Lifetime Spectrometer C11367 and a Hamamatsu Absolute PL Quantum Yield Spectrometer C11347. FT-IR was performed on a Thermo Scientific Nicolet iS10 spectrometer. HRTEM images were obtained on Jeol-2100F. The TGA was measured on a Q50 thermal analyzer by heating under a flow of $\mathrm{N}_{2}$ gas to $900{ }^{\circ} \mathrm{C}$ at a rate of $10{ }^{\circ} \mathrm{C} \mathrm{min}^{-1}$. The zeta potential was performed on a Malvern Zetasizer Nano ZS (ZS 90, UK) at room temperature. Circular dichroism spectra were recorded on an Applied Photophysics Chirascan CD spectrometer at $25{ }^{\circ} \mathrm{C}$ under a nitrogen atmosphere.

\section{Antioxidant activity}

The scavenging activity of the C-dots for DPPH free radicals was evaluated in methanol solution at $517 \mathrm{~nm}$ via UV-vis spectroscopy. DPPH was added into the methanol solution with various concentrations of C-dots at a final DPPH concentration of 50 $\mu \mathrm{M}$. The reacted solutions were incubated in the dark for $1.5 \mathrm{~h}$. The decreased absorption was calculated as below:

$$
\text { Inhibition }(\%)=100 \times\left(A_{\mathrm{c}}-A_{\mathrm{s}}\right) / A_{\mathrm{c}}
$$

where $A_{\mathrm{c}}$ and $A_{\mathrm{s}}$ are the absorbance of the solution in the absence and presence of C-dots. The $\mathrm{EC}_{50}$ was the half maximal effective concentration, corresponding to the concentration required to reduce the DPPH radicals by $50 \%$.

\section{WST assay}

The cytotoxicity of the C-dots was evaluated by WST assay. MCF7 cells were seeded onto a 96-well plate $\left(10^{4}\right.$ cells per well $)$ for 24 h. Phosphate buffered saline (PBS) solutions with various concentrations of C-dots $\left(0.2-4.0 \mathrm{mg} \mathrm{mL}^{-1}\right)$ were added to each well and incubated for another $24 \mathrm{~h}$, using DMEM medium as a control. Each well was washed three times with PBS, followed by the addition of $10 \mu \mathrm{L}$ of WST solution for another $2 \mathrm{~h}$ incubation. The absorbance at $450 \mathrm{~nm}$ was measured on a plate reader (PerkinElmer Victor X4). The cell viability was calculated according to the following equation:

$$
\text { Cell viability }(\%)=100 \times\left(\mathrm{OD}_{\mathrm{s}}-\mathrm{OD}_{\mathrm{b}}\right) /\left(\mathrm{OD}_{\mathrm{c}}-\mathrm{OD}_{\mathrm{b}}\right)
$$

where $\mathrm{OD}_{\mathrm{s}}, \mathrm{OD}_{\mathrm{b}}$ and $\mathrm{OD}_{\mathrm{c}}$ are the absorbances of the sample, background and control at $450 \mathrm{~nm}$, respectively.

\section{Hemolysis assay}

Human red blood cells (HRBCs) were separated from whole blood via centrifugation at $1500 \mathrm{rpm}$ for $10 \mathrm{~min}$ and further washed five times with sterile PBS $(\mathrm{pH}=7.4)$. The packed HRBCs were dispersed in $4 \mathrm{~mL}$ of PBS. $200 \mu \mathrm{L}$ of diluted HRBCs was transferred to $600 \mu \mathrm{L}$ of PBS solution with various concentrations of C-dots. $600 \mu \mathrm{L}$ of DI water and PBS were used to replace the $\mathrm{C}$-dot solution as positive and negative controls. All of the samples were shaken for $3 \mathrm{~h}$ at $37{ }^{\circ} \mathrm{C}$ and then centrifuged at $1500 \mathrm{rpm}$ for $10 \mathrm{~min}$. The supernatant solution was recorded via UV-vis spectroscopy at $540 \mathrm{~nm}$. The hemolytic rate was calculated using the following formula:

$$
\text { Hemolytic rate }(\%)=100 \times\left(A_{\mathrm{s}}-A_{\mathrm{n}}\right) /\left(A_{\mathrm{p}}-A_{\mathrm{n}}\right)
$$

where $A_{\mathrm{s}}, A_{\mathrm{p}}$ and $A_{\mathrm{n}}$ are the absorbances of the sample, and the positive and negative controls at $540 \mathrm{~nm}$. 


\section{Histology examination}

The BALB/C nude mice ( $20 \pm 2 \mathrm{~g}$ ) were divided into a control group and three experimental groups $(n=12)$. After anesthetization with isoflurane, the mice were injected with PBS (control group) and C-dot solutions at various concentrations (0.1, 1.0, and $10 \mathrm{mg} \mathrm{mL}^{-1}$ ) by tail vein injection. The final concentrations of the C-dots were $0.5,5$, and $10 \mathrm{mg} \mathrm{kg}^{-1}$ in the experimental groups. Typically the heart, liver, spleen, lung and kidney were harvested after $24 \mathrm{~h}$ treatment and fixed in $4 \%$ of paraformaldehyde for another $24 \mathrm{~h}$. The organs were dehydrated gradually using various concentrations of ethanol, and then embedded in liquid paraffin $(5 \mu \mathrm{m})$. The sliced organs were stained with hematoxylin and eosin (H\&E) and observed under an Olympus BX51 microscope.

\section{Cellular imaging}

MCF-7 cells were seeded on $6 \mathrm{~mm}$ glass coverslips $\left(10^{5}\right.$ cells per slip) and incubated for $24 \mathrm{~h}$. The medium was replaced by a Cdot solution with a concentration of $5 \mathrm{mg} \mathrm{mL}^{-1}$. After incubation for $4 \mathrm{~h}$, each well was washed with PBS three times. The cells were imaged using a confocal laser scanning microscope (TCS SP5, Leica, Germany) and illuminated with $405 \mathrm{~nm}$, $458 \mathrm{~nm}$ and $514 \mathrm{~nm}$ lasers.

\section{Live subject statement}

All experiments were performed in strict compliance with the relevant laws and institutional guidelines of Guangxi Medical University, Nanning, China (20140307A, 20140307B), and approved by the Ethics Committee of Guangxi Medical University. We obtained informed consent for any experimentation with human subjects.

\section{Results and discussion}

\section{XPS and FT-IR}

The surface elements of the C-dots were characterized by XPS (Fig. 1a), confirming that the surfaces of the C-dots were composed of five elements, including carbon $(\mathrm{C}),{ }^{19}$ oxygen $(\mathrm{O}),{ }^{19}$ potassium (K), ${ }^{20}$ calcium $(\mathrm{Ca}),{ }^{21}$ and silicon $(\mathrm{Si}) .{ }^{19}$ The carbon (C) and oxygen $(\mathrm{O})$ peaks exhibited stronger characteristic peaks, and the content of $\mathrm{C}$ and $\mathrm{O}$ was $69.26 \%$ and $22.17 \%$, respectively. The content of the other three elements ( $\mathrm{K}, \mathrm{Ca}$, and $\mathrm{Si}$ ), however, was only $8.57 \%$. The XPS spectrum of $\mathrm{C}_{1 \mathrm{~s}}$ could be deconvoluted into five small peaks which were ascribed to three types of carbon bond (Fig. 1b), corresponding to $\mathrm{C}=\mathrm{C}(283.5$ $\mathrm{eV}), \mathrm{C}-\mathrm{C}(284.8 \mathrm{eV})$ and $\mathrm{O}=\mathrm{C}-\mathrm{O}(287.1 \mathrm{eV}, 291.8 \mathrm{eV}$ and 294.4 $\mathrm{eV}) .{ }^{19} \mathrm{In}$ the $\mathrm{O}_{1 \mathrm{~s}}$ spectrum, the peaks at $530.4 \mathrm{eV}$ and $531.8 \mathrm{eV}$ were ascribed to $\mathrm{C}=\mathrm{O}$ and $\mathrm{C}-\mathrm{OH} / \mathrm{C}-\mathrm{O}-\mathrm{C}^{22}$ (Fig. 1c). The functional groups of the C-dots were further analysed by FT-IR (Fig. 1d). The broad band at $3207 \mathrm{~cm}^{-1}$ is the characteristic absorption band of $\mathrm{O}-\mathrm{H},{ }^{8,23}$ while the bands at 2983, 1565, $1402 \mathrm{~cm}^{-1}$ were attributed to $-\mathrm{C}-\mathrm{H}, \mathrm{C}=\mathrm{O},-\mathrm{C}=\mathrm{C}$, respectively. ${ }^{24}$ The bands in the range of $1400-1000 \mathrm{~cm}^{-1}$ were associated with $\mathrm{C}-\mathrm{O}$ and $\mathrm{Si}-\mathrm{O}-\mathrm{Si}$ stretching vibrations. ${ }^{19}$ The XPS and FT-IR results further verified that hydroxyl, carboxyl and carbon-
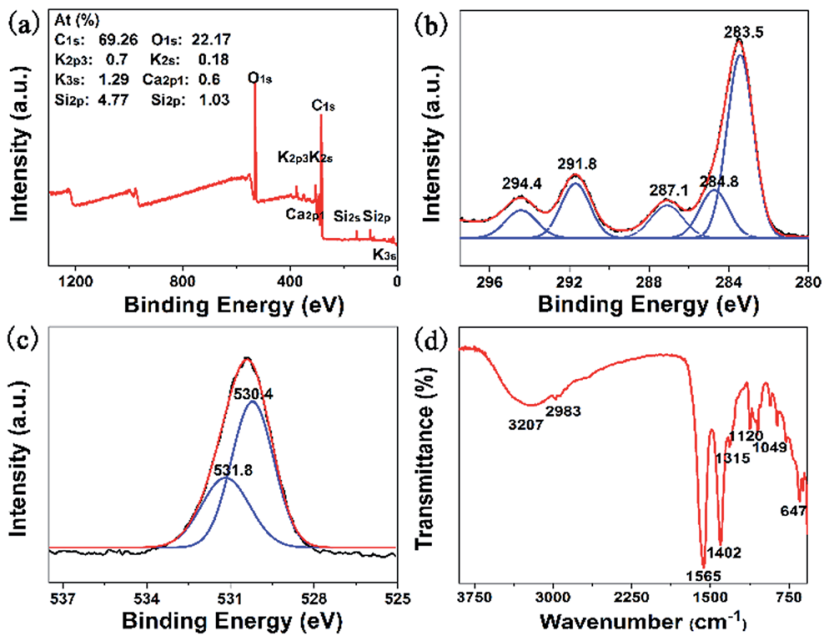

Fig. 1 (a) The XPS survey spectrum; (b) $C_{1 s}$ and (c) $O_{1 s}$ : experimental curves (black lines), spectral fitting (red lines), deconvoluted peaks (blue lines); (d) FT-IR spectrum of C-dots.

carbon double bond functional groups were on the surfaces of the C-dots.

\section{NMR characterization}

The chemical structure of the C-dots was characterized by NMR in $\mathrm{D}_{2} \mathrm{O}$ (Fig. $\mathrm{S} 1 \dagger$ ). Signals in the range of 0.91 to $4.15 \mathrm{ppm}$ were assigned to protons of the carbons conjugated to the furan ringlike structure in the ${ }^{1} \mathrm{H}$ NMR spectrum (Fig. S1a $\dagger$ ). The signals of the aromatic protons were relatively low and appeared in the range of 6.16-8.46 ppm (Fig. S1a $\dagger$ inset). To the best of our knowledge, the $\mathrm{C}-\mathrm{C}$ network structure of the C-dots was amorphous. The biomass-derived carbon could exploit the furan ring-like structural motif after pyrolysis, ${ }^{25}$ such as in glucose and fructose, which were the major constituents of the sugarcane molasses. Herein, the furan ring-like structure was generated in the chemical structure of C-dots derived from sugarcane molasses after hydrothermal carbonization. Meanwhile, the chemical structure of the C-dots was further characterized by the ${ }^{13} \mathrm{C}$ NMR spectrum (Fig. S1b $\dagger$ ). The characteristic peaks in the range of 8.38-68.2 ppm were attributed to the aliphatic carbon while the other peaks were assigned to the carbonyl carbons and aromatic carbons. ${ }^{26}$

\section{UV-vis absorbance, fluorescence of C-dots and XRD}

Two typical absorption peaks at $260 \mathrm{~nm}$ and $320 \mathrm{~nm}$ were observed in the UV-vis absorption spectrum (Fig. 2a), which were attributed to the $\pi-\pi^{*}$ transition of the aromatic $\mathrm{sp}^{2}$ domains and the $n-\pi^{*}$ transition of the $\mathrm{C}=\mathrm{O}$ group, respectively. ${ }^{19}$

The dispersed C-dot solution was light brown under sunlight, but emitted strong blue fluorescence upon $365 \mathrm{~nm}$ UV light irradiation. While varying the excitation wavelength from $285 \mathrm{~nm}$ to $335 \mathrm{~nm}$, the emission wavelength changed (Fig. S2a $\dagger$ ). After normalization of the emission intensity, red shift of the emission wavelength was observed (inset of 


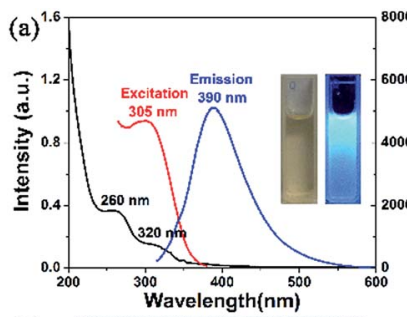

(c)

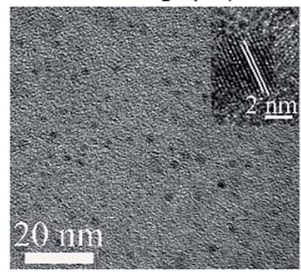

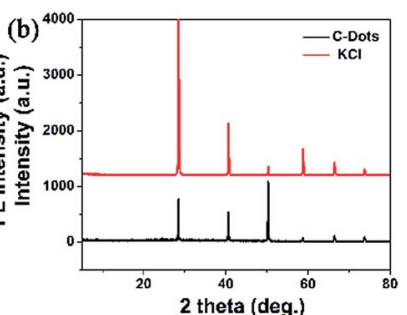

(d)

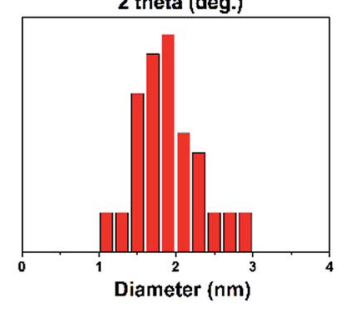

Fig. 2 (a) UV-vis absorption spectrum and fluorescence spectra; (b) XRD; (c) HRTEM images; (d) statistical size distribution of C-dots obtained from HRTEM images.

Fig. S2a $\dagger$ ). Moreover, the emission fluorescence intensity decreased, and the maximum intensity was observed at $390 \mathrm{~nm}$ upon excitation at $305 \mathrm{~nm}$ (Fig. S2a $\dagger$ ). The mechanism of the excitation-dependent fluorescence properties may be derived from the distribution of size and emissive traps on the surfaces of the C-dots. ${ }^{19} \mathrm{Li}$ et al. reported diverse luminescence in C-dots with a size of 1.2-3.8 $\mathrm{nm}$ due to a quantum-sized graphite fragment. ${ }^{27}$ Yeh et al. showed that the luminescence colour of graphene oxide quantum dots varied as the size decreased, which was associated with electron transitions. ${ }^{28}$ Although the mechanism of the excitation-dependent fluorescence properties was in its infancy, there was mounting evidence to elucidate it. In addition, the quantum yield was $5.8 \%$. The crystal structure of the C-dots was determined by XRD. Fig. 2b depicts six characteristic diffraction peaks at $2 \theta=28.4^{\circ}, 40.7^{\circ}, 50.4^{\circ}, 58.8^{\circ}$, $66.6^{\circ}$, and $73.8^{\circ}$, which were ascribed to the characteristic peaks of KCl. The C-dots exploited the low carbon-lattice-structure ${ }^{29}$ and exhibited carbon characteristic peaks at $25^{\circ}$, but this was so weak that it could not be observed due to the strong signals of the $\mathrm{KCl}$ crystal.

\section{HRTEM, TGA analysis, photo-stability and antioxidant activity}

The morphology of the C-dots is displayed in the HRTEM images (Fig. 2c), exhibiting the spherical shaped C-dots with an average diameter of $1.9 \mathrm{~nm}$ (Fig. 2d) and a lattice fringe distance of $0.23 \mathrm{~nm}$. The zeta potential of the C-dots was $-4.27 \mathrm{mV}$. The thermal stability of the C-dots was assessed by TGA (Fig. S2b $\dagger$ ). Initially, the weight loss was $8.56 \%$ at $200{ }^{\circ} \mathrm{C}$ due to the evaporation of water molecules or damage of weak interactions. ${ }^{30}$ As the temperature was raised to $465{ }^{\circ} \mathrm{C}$ the weight loss was $35.32 \%$, which may be attributed to the decomposition of organic functional groups, ${ }^{31}$ and they kept an almost constant weight between $465{ }^{\circ} \mathrm{C}$ and $590{ }^{\circ} \mathrm{C}$. Nevertheless, the weight loss of the C-dots further changed between $590{ }^{\circ} \mathrm{C}$ and $900{ }^{\circ} \mathrm{C}$, probably due to the release of pyrogas. ${ }^{32}$ Upon continuous UV light illumination at $365 \mathrm{~nm}$ for $180 \mathrm{~min}$, the fluorescence

intensity of the C-dots displayed no obvious change, exhibiting excellent photo-stability and stronger resistance to photobleaching (Fig. S2c $\dagger$ ). The antioxidant activity of the C-dots was studied by a DPPH-based assay. ${ }^{5}$ The radical scavenging profile showed typical dose-dependence in the presence of the C-dots (Fig. S2d $\dagger$ ). The $\mathrm{EC}_{50}$ of the C-dots derived from sugarcane molasses was $0.514 \mathrm{mg} \mathrm{mL}^{-1}$, exhibiting stronger antioxidant activity. Sugarcane molasses, possessing stronger antioxidant activity owing to its rich phenolic constituents, ${ }^{33,34}$ was carbonized and recombined at $250{ }^{\circ} \mathrm{C}$, so that partial phenolic hydroxyl groups could remain on the surface of the C-dots, exhibiting stronger antioxidant activity.

\section{The effect on C-dots and sensing for $\mathrm{Fe}^{3+}$}

As revealed in Fig. 3a, no appreciable change in the fluorescence intensity was observed in the $\mathrm{pH}$ range of $6-12$, yet a slight decrease occurred from $\mathrm{pH} 5$ to 3 , demonstrating that the $\mathrm{C}$ dots were more suitable for a solution with a $\mathrm{pH}$ value between 6 and 12. No obvious fluorescence intensity change was observed even at a higher $\mathrm{NaCl}$ concentration of $1 \mathrm{M}$ (Fig. 3b), indicating that the C-dots exhibited excellent stability in the high ionic strength solution. Based on the interactions between the C-dots and potential interfering biomolecules, the fluorescence of the C-dots was assessed in various solutions with amino acids as well as GSH (Fig. 3c). No apparent change occurred, indicating that the fluorescence of the C-dots suffered no interference from the amino acids or GSH. Besides, the fluorescence variation of the C-dots after the addition of various metal ions is shown in Fig. 3d. Notice that the fluorescence intensity of the C-dots suffered no significant interference from several metal ions, including $\mathrm{K}^{+}, \mathrm{Ca}^{2+}, \mathrm{Mg}^{2+}, \mathrm{Cd}^{2+}, \mathrm{La}^{3+}, \mathrm{Pb}^{2+}$ and $\mathrm{Mn}^{2+}$, while the fluorescence intensity was slightly interfered with by $\mathrm{Co}^{2+}, \mathrm{Cr}^{3+}, \mathrm{Fe}^{2+}$ and $\mathrm{Cu}^{2+}$ ions due to the electron transfer mechanism. ${ }^{35}$ Moreover, a sharp decrease in the fluorescence intensity was revealed in the $\mathrm{Fe}^{3+}$ solution. As previously deduced, phenolic hydroxyl groups may be present on the
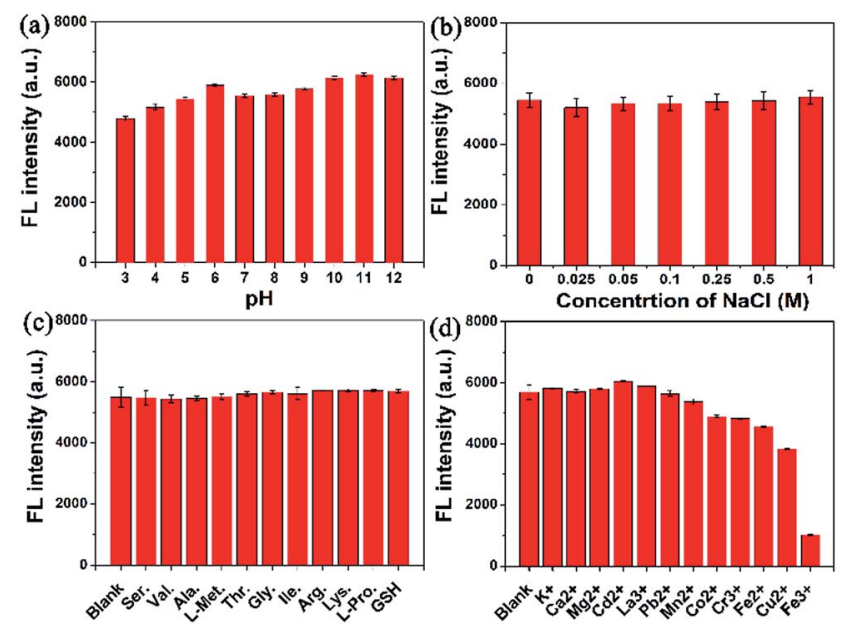

Fig. 3 The effect on the fluorescence intensity of the $\mathrm{C}$-dots at $390 \mathrm{~nm}\left(0.25 \mathrm{mg} \mathrm{mL}^{-1}\right.$ ) from: (a) $\mathrm{pH}$; (b) $\mathrm{NaCl}$; (c) amino acids (500 $\mu \mathrm{M})$; (d) metal ions $(500 \mu \mathrm{M})$. 
surface of the C-dots, therefore the interaction between the phenolic hydroxyl groups on the surface of the C-dots and $\mathrm{Fe}^{3+}$ resulted in a decrease in the fluorescence intensity of the $\mathrm{C}$ dots. ${ }^{36}$

With the addition of various concentrations of $\mathrm{Fe}^{3+}$ to the $\mathrm{C}$ dot solutions, a decline in the fluorescence intensity was observed (Fig. 4a). When the concentration of $\mathrm{Fe}^{3+}$ was $700 \mu \mathrm{M}$, the fluorescence was almost quenched. A good linear relationship was obtained in the range of $0-100 \mu \mathrm{M}$ (Fig. 4b). The fluorescence quenching efficiency was $\left(F_{0}-F\right) / F_{0}=0.0036 x-$ 0.0264 , with a correlation coefficient $\left(R^{2}\right)$ of 0.9961 , where $F_{0}$ and $F$ were the fluorescence intensities of the C-dots at $390 \mathrm{~nm}$ in the absence and presence of $\mathrm{Fe}^{3+}$ ions. ${ }^{37}$ The lowest detection limit (LOD) was calculated to be $1.46 \mu \mathrm{M}$ based on the standard deviation $(\sigma)$ of the blank signal $(n=3)$ and the slope of the calibration curve $(S)$ at levels approximating the LOD according to the formula LOD $=3 \times(\sigma / S) .^{38}$

\section{Cytotoxicity assay and hemolysis assay}

The relative viabilities of the MCF-7 cells were assessed by WST assay in vitro. ${ }^{39}$ The results showed that the MCF-7 cells' viabilities were over $90 \%$ after $24 \mathrm{~h}$ incubation with various concentrations of C-dots $\left(0.2-3 \mathrm{mg} \mathrm{mL}^{-1}\right)$. Even at a higher concentration of $4.0 \mathrm{mg} \mathrm{mL} \mathrm{m}^{-1}$, the cells' viabilities were still $97.29 \pm 0.35 \%$, indicating excellent biocompatibility with the MCF-7 cells (Fig. 5a). A hemolysis assay was performed to further evaluate the blood biocompatibility in vitro (Fig. 5b). The solution in deionized water (positive control) turned red due to the release of hemoglobin from red blood cells while hemolysis did not occur in the PBS solutions (negative control). No obvious hemolytic effect was observed in the PBS solutions with different C-dot concentrations $\left(0.2-2.0 \mathrm{mg} \mathrm{mL} \mathrm{m}^{-1}\right)$ and the hemolysis percentages were $0.47 \%, 0.2 \%, 0.2 \%, 0.28 \%, 0.18 \%$, and $0.46 \%$, respectively. These results showed that the C-dots have negligible hemolytic activity.

The conformation of the protein was also investigated after addition of the C-dots in vitro (Fig. 5c). Bovine serum albumin (BSA) was chosen as the protein model, the secondary structure of which was recorded using circular dichroism (CD) spectroscopy. The CD results were treated with the mean residue ellipticity (MRE) by the formulas: ${ }^{40}$

$$
\mathrm{MRE}=\mathrm{CD}_{\mathrm{obs}} / 10 C_{\mathrm{p}} n l
$$
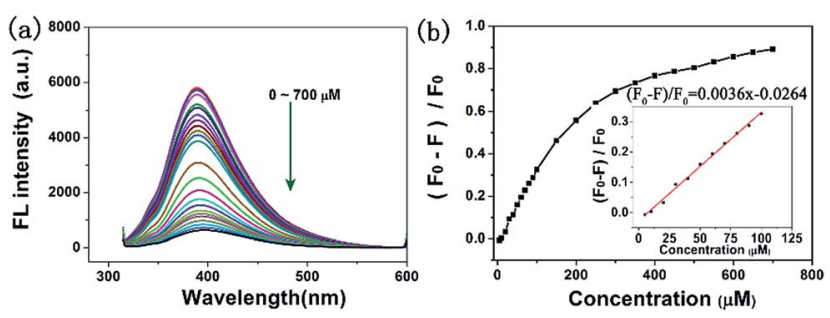

Fig. 4 (a) Photoluminescence emission spectra of C-dots $(0.25 \mathrm{mg}$ $\mathrm{mL}^{-1}$ ) in the presence of various concentrations of $\mathrm{Fe}^{3+} ;$ (b) the curve of the fluorescence quenching efficiency versus concentration of $\mathrm{Fe}^{3+}$.

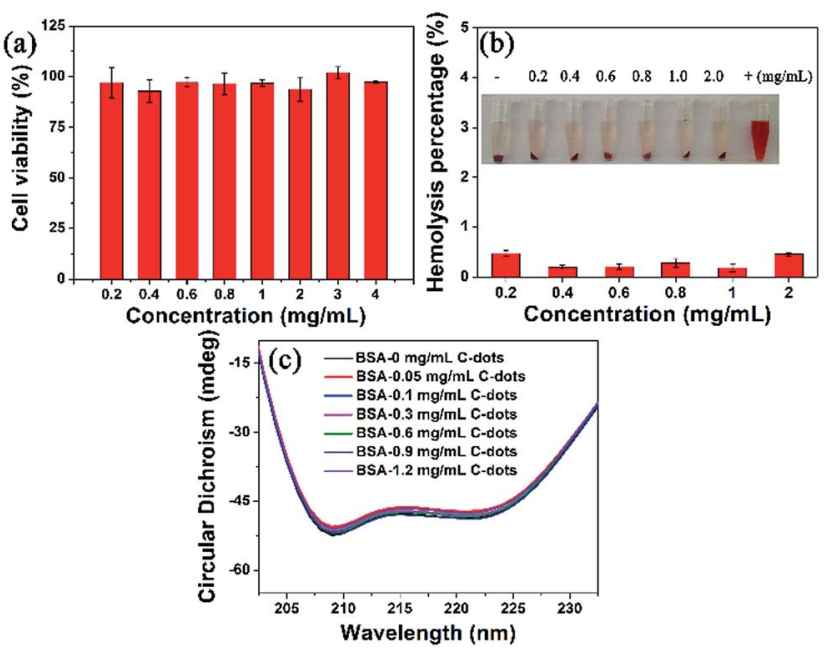

Fig. 5 (a) Viabilities of MCF-7 cells incubated with various concentrations of C-dots for $24 \mathrm{~h}$ using a WST assay; (b) a hemolysis assay with deionized water and PBS as positive and negative controls; (c) CD spectra of the BSA/C-dots system.

$$
\alpha \text {-Helix }(\%)=100 \times(-\operatorname{MRE}-4000) /(33000-4000)
$$

In this work, the $\mathrm{CD}_{\text {obs }}$ is the observed ellipticity in millidegrees at $209 \mathrm{~nm}$, where the final concentration of BSA $\left(C_{\mathrm{p}}\right)=4$ $\times 10^{-6} \mathrm{M}$, the number of amino acid residues $(n)=583$ and the path length of the cell $(l)=0.1 \mathrm{~cm}$. No obvious secondary structure change in the BSA occurred at $209 \mathrm{~nm}$ and $222 \mathrm{~nm}$ (Fig. 5c), corresponding to the decreases in the $\alpha$-helix content of $4.18 \%, 1.86 \%, 2.55 \%, 1.16 \%, 0.7 \%$, and $3.25 \%$ in the concentration range of $0.05-1.2 \mathrm{mg} \mathrm{mL}^{-1}$, indicating that the $\mathrm{C}$ dot had a slight weak effect on the $\alpha$-helix structure of BSA.

In vivo histological toxicity analysis was conducted to assess cell damage of the mice's main organs including the heart, liver, spleen, lung and kidney (Fig. 6). Compared with the control groups, there was no obvious damage in the C-dot treated groups, such as inflammatory response, pulmonary fibrosis, necrosis or damage to the morphologies of the main organs, indicating that the C-dots had no appreciable side effects on the main organs.

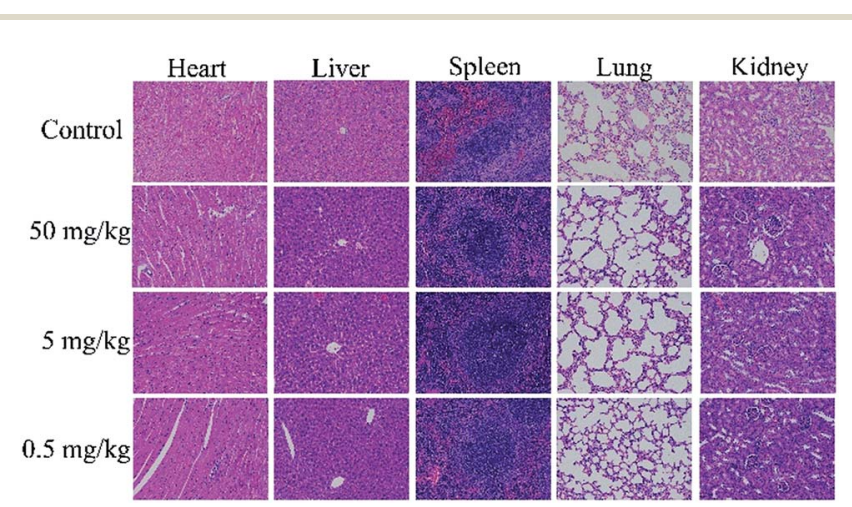

Fig. 6 H\&E stained tissue sections of heart, liver, spleen, lung and kidney after $24 \mathrm{~h}$. 

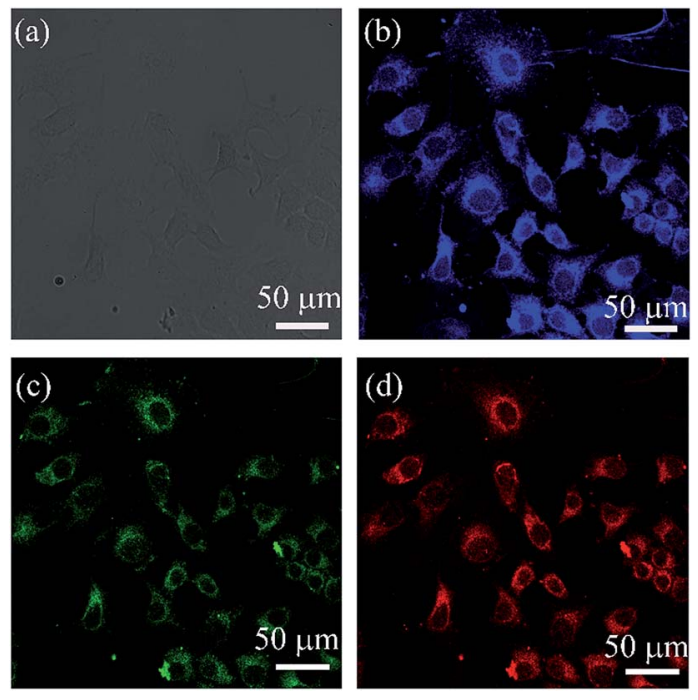

Fig. 7 CLSM images of the C-dots incubated with MCF-7 cells for $4 \mathrm{~h}$ at $5 \mathrm{mg} \mathrm{mL}^{-1}$ under (a) bright field, (b) $405 \mathrm{~nm}$, (c) $458 \mathrm{~nm}$, and (d) $514 \mathrm{~nm}$.
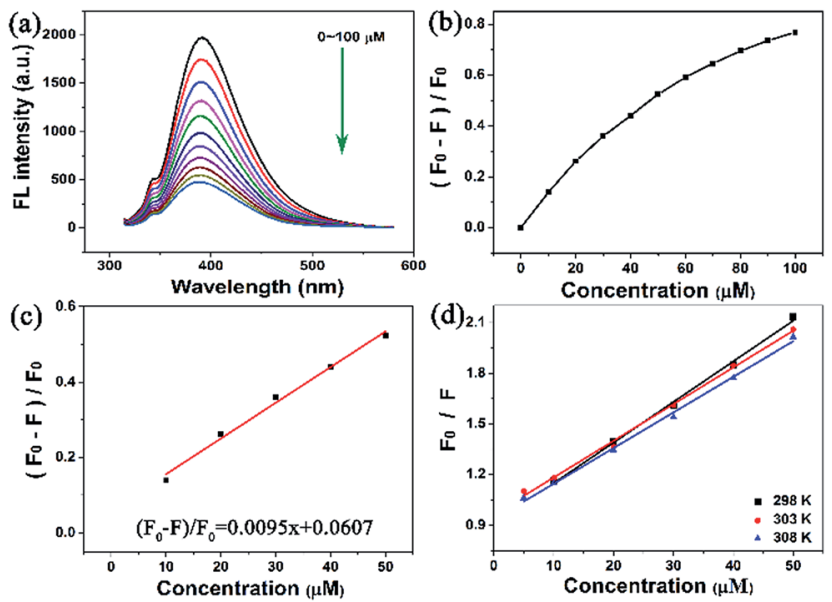

Fig. 8 (a) Photoluminescence emission spectra of C-dots $(0.1 \mathrm{mg}$ $\mathrm{mL}^{-1}$ ) in the presence of various concentrations of sunset yellow; (b) the curve of the fluorescence quenching efficiency versus concentrations of sunset yellow; (c) the linear calibration plot for detection of sunset yellow; (d) Stern-Volmer plots for the C-dots/sunset yellow system at different temperatures.

\section{Cellular imaging}

Bioimaging of the C-dots was investigated by confocal laser scanning microscopy (CLSM). In the bright-field, the MCF-7 cells exhibited integral morphology after $4 \mathrm{~h}$ incubation with the C-dots (Fig. 7a). The MCF-7 cells emitted blue, green and red fluorescence upon excitation at $405 \mathrm{~nm}, 458 \mathrm{~nm}$ and $514 \mathrm{~nm}$ (Fig. 7b-d). It was easily found that the C-dots were mainly located in the cell membrane and cytoplasm, but weak fluorescence was emitted from the nucleus, showing an efficient cellular uptake and excellent characteristic wavelengthdependent emission of the C-dots.

\section{Sensing for sunset yellow and the mechanism of fluorescence quenching}

In this work, sunset yellow was sensed through fluorescence emission spectrometry. It is worth pointing out that a significant fluorescence intensity change was observed in the range of $0-100 \mu \mathrm{M}$ (Fig. 8a and b), revealing that the fluorescence of the C-dots decreased when the sunset yellow dosage increased. The fluorescence quenching efficiency was $\left(F_{0}-F\right) / F_{0}=0.0095 x+$ 0.0607 , and the fluorescence intensity of the C-dots exhibited an excellent linear relationship in the range of $0-60 \mu \mathrm{M}$ (Fig. 8c), with a correlation coefficient $\left(R^{2}\right)$ of 0.9915 . The LOD was calculated to be $0.399 \mu \mathrm{M}$ according to the formula: $\mathrm{LOD}=3 \times$ $(\sigma / S)(n=3)$.

To understand the mechanism of fluorescence quenching, the fluorescence intensity of the C-dots was assessed using the Stern-Volmer equation:

$$
F_{0} / F=1+K_{\mathrm{SV}}[\mathrm{Q}]=1+K_{\mathrm{q}} \tau_{0}[\mathrm{Q}]
$$

where $F_{0}$ and $F$ are the fluorescence intensities of the C-dots at $309 \mathrm{~nm}$ in the absence and presence of sunset yellow, respectively; $K_{\mathrm{Sv}}$ and $K_{\mathrm{q}}$ were the Stern-Volmer quenching constant and the quenching constant, respectively; [Q] was the concentration of the sunset yellow; $\tau_{0}$ was the lifetime of the C-dots in the blank solution, where $\tau_{0}=6.00 \mathrm{~ns}$ (Table S1 $\dagger$ ). The fluorescence intensity of the C-dots was analysed at $298 \mathrm{~K}, 303 \mathrm{~K}$, and $308 \mathrm{~K}$ according to the Stern-Volmer equation (Fig. 8d) and the $K_{\mathrm{Sv}}$ and $K_{\mathrm{q}}$ are summarized in Table 1 . The $K_{\mathrm{q}}$ decreased with an elevation in the temperature and was far larger than the maximum dynamic quenching constant $\left(2.0 \times 10^{10} \mathrm{~L} \mathrm{~mol}^{-1}\right.$ $\mathrm{s}^{-1}$ ) at each temperature, indicating that the mechanism of fluorescence quenching could be based on static quenching. ${ }^{\mathbf{4 1}}$ Additionally, it was apparent to observe the reduction in the fluorescence lifetime with an increase in the concentration of sunset yellow (Fig. S3a†). The UV-vis spectrum shows that the characteristic absorbance intensity of the C-dots at $260 \mathrm{~nm}$ decreased, with a blue shift (Fig. S3b†). The surface charges of the C-dots and the sunset yellow were $-4.27 \mathrm{mV}$ and $1.32 \mathrm{mV}$, respectively. The results enumerated above indicated that a ground-state complex would be formed owing to electrostatic interaction between the C-dots and sunset yellow.

Table 1 Stern-Volmer quenching constants of the C-dots and sunset yellow at different temperatures

\begin{tabular}{lllll}
\hline$T(\mathrm{~K})$ & Equation & $R^{2}$ & $K_{\mathrm{SV}}\left(\mathrm{L} \mathrm{mol}^{-1}\right)$ & $K_{\mathrm{q}}\left(\mathrm{L} \mathrm{mol}^{-1} \mathrm{~s}^{-1}\right)$ \\
\hline 298 & $F_{\mathrm{o}} / F=0.02409[\mathrm{Q}]+0.90813$ & 0.9965 & $2.0029 \times 10^{4}$ & $3.3382 \times 10^{12}$ \\
303 & $F_{\mathrm{o}} / F=0.02176[\mathrm{Q}]+0.965$ & 0.9959 & $1.9871 \times 10^{4}$ & $3.3118 \times 10^{12}$ \\
308 & $F_{0} / F=0.02111[\mathrm{Q}]+0.93502$ & 0.9963 & $1.6990 \times 10^{4}$ & $2.8317 \times 10^{12}$
\end{tabular}


A comparison of the analytical parameters of this work and previous works for $\mathrm{Fe}^{3+}$ and sunset yellow determination are summarized in Table S2.† The C-dots derived from sugarcane molasses were not ultrasensitive for detecting $\mathrm{Fe}^{3+}$ and sunset yellow due to weak interaction. We will focus on appropriate strategies to address this issue in future work, e.g. aptamers.

\section{Conclusions}

In summary, a facile fabrication of C-dots derived from sugarcane molasses was successfully developed via a hydrothermal pyrolysis method. The spherical C-dots with a diameter of $1.9 \mathrm{~nm}$ emitted blue photoluminescence under UV light at $365 \mathrm{~nm}$ and the quantum yield was 5.8\%. The C-dots exhibited more stability in the $\mathrm{pH}$ value range from 6 to 12 and outstanding tolerance to $\mathrm{NaCl}$ solution. No obvious fluorescence intensity changes occurred in the amino acids and several metal ion solutions. Moreover, the fluorescence suffered interference by $\mathrm{Fe}^{3+}$ ions, which was successfully exploited to sense $\mathrm{Fe}^{3+}$ ions in a linear range from 0 to $100 \mu \mathrm{M}$. The cytotoxicity of the C-dots was assessed both in vitro and in vivo, demonstrating that the C-dots possessed excellent biocompatibility with MCF-7 cells, red blood cells, BSA and the main organs. Moreover, the Cdots could emit blue, green and red fluorescence in the MCF-7 cells resulting from a wavelength-dependent characteristic. Additionally, the C-dots were able to sense sunset yellow in the linear range from 0 to $60 \mu \mathrm{M}$ due to fluorescence quenching, which may be caused by static quenching.

\section{Conflicts of interest}

The authors declare no competing financial interest.

\section{Acknowledgements}

This work was financially supported by the Guangxi Natural Science Foundation of China (2016GXNSFBA380104), the China Postdoctoral Science Foundation (2016M602916XB), the Guangxi Distinguished Experts Special Foundation of China, the Science Foundation of Guangxi Academy of Sciences (2017YJJ23019), and the Open Research Project from Key Laboratory of High Incidence Diseases Prevention and Control of Guangxi Universities and Colleges (02402214003-1602).

\section{References}

1 H. Yu, R. Shi, Y. Zhao, G. I. N. Waterhouse, L.-Z. Wu, C.-H. Tung and T. Zhang, Adv. Mater., 2016, 28, 9454-9477.

2 H. Ding, F. Du, P. Liu, Z. Chen and J. Shen, ACS Appl. Mater. Interfaces, 2015, 7, 6889-6897.

3 Q. Zhu, F. Pan, Y. Tian, W. Tang, Y. Yuan and A. Hu, RSC Adv., 2016, 6, 29441-29447.

4 A. Kumar, A. R. Chowdhuri, D. Laha, S. Chandra, P. Karmakar and S. K. Sahu, RSC Adv., 2016, 6, 58979-58987.

5 S. Zhao, M. Lan, X. Zhu, H. Xue, T.-W. Ng, X. Meng, C.-S. Lee, P. Wang and W. Zhang, ACS Appl. Mater. Interfaces, 2015, 7, 17054-17060.
6 Y. Su, B. Shi, S. Liao, J. Zhao, L. Chen and S. Zhao, ACS Sustainable Chem. Eng., 2016, 4, 1728-1735.

7 L. Guo, J. Ge, W. Liu, G. Niu, Q. Jia, H. Wang and P. Wang, Nanoscale, 2016, 8, 729-734.

8 S. Y. Park, H. U. Lee, E. S. Park, S. C. Lee, J.-W. Lee, S. W. Jeong, C. H. Kim, Y.-C. Lee, Y. S. Huh and J. Lee, ACS Appl. Mater. Interfaces, 2014, 6, 3365-3370.

9 Y. Asikin, M. Takahashi, T. Mishima, M. Mizu, K. Takara and K. Wada, Food Chem., 2013, 141, 466-472.

10 M.-Y. Jung, B.-S. Park, J. Lee and M.-K. Oh, Bioresour. Technol., 2013, 139, 21-27.

11 L. Weifeng, M. Suhua, Z. Shengbiao and S. Xiaodong, J. Therm. Anal. Calorim., 2014, 118, 83-91.

12 J. Moncada, M. M. El-Halwagi and C. A. Cardona, Bioresour. Technol., 2013, 135, 533-543.

13 S. Dinç, Zuckerindustrie. Sugar industry, 2016, 141, 560-564. 14 X. Qiu, L. Lu, J. Leng, Y. Yu, W. Wang, M. Jiang and L. Bai, Food Chem., 2016, 190, 889-895.

15 M. Gómez, V. Arancibia, C. Rojas and E. Nagles, Int. J. Electrochem. Sci., 2012, 7, 7493-7502.

16 H. Wu, J.-b. Guo, L.-m. Du, H. Tian, C.-x. Hao, Z.-f. Wang and J.-y. Wang, Food Chem., 2013, 141, 182-186.

17 E. Heidarizadi and R. Tabaraki, Talanta, 2016, 148, 237-246.

18 Y. Xing, M. Meng, H. Xue, T. Zhang, Y. Yin and R. Xi, Talanta, 2012, 99, 125-131.

19 W.-J. Wang, X. Hai, Q.-X. Mao, M.-L. Chen and J.-H. Wang, ACS Appl. Mater. Interfaces, 2015, 7, 16609-16616.

20 S. S. Kim, T. V. Khai, V. Kulish, Y.-H. Kim, H. G. Na, A. Katoch, M. Osada, P. Wu and H. W. Kim, Chem. Mater., 2015, 27, 4222-4228.

21 Q. Li, L. Dong, W. Deng, Q. Zhu, Y. Liu and C. Xiong, J. Am. Chem. Soc., 2009, 131, 9148-9149.

22 X. Wen, L. Shi, G. Wen, Y. Li, C. Dong, J. Yang and S. Shuang, Sens. Actuators, B, 2015, 221, 769-776.

23 T. Feng, X. Ai, G. An, P. Yang and Y. Zhao, ACS Nano, 2016, 10, 4410-4420.

24 R. Purbia and S. Paria, Biosens. Bioelectron., 2016, 79, 467475.

25 A. Prasannan and T. Imae, Ind. Eng. Chem. Res., 2013, 52, 15673-15678.

26 J.-Y. Li, Y. Liu, Q.-W. Shu, J.-M. Liang, F. Zhang, X.-P. Chen, X.-Y. Deng, M. T. Swihart and K.-J. Tan, Langmuir, 2017, 33, 1043-1050.

27 H. Li, X. He, Z. Kang, H. Huang, Y. Liu, J. Liu, S. Lian, C. H. A. Tsang, X. Yang and S.-T. Lee, Angew. Chem., Int. Ed., 2010, 49, 4430-4434.

28 T.-F. Yeh, W.-L. Huang, C.-J. Chung, I. T. Chiang, L.-C. Chen, H.-Y. Chang, W.-C. Su, C. Cheng, S.-J. Chen and H. Teng, J. Phys. Chem. Lett., 2016, 7, 2087-2092.

29 S. Zhu, Q. Meng, L. Wang, J. Zhang, Y. Song, H. Jin, K. Zhang, H. Sun, H. Wang and B. Yang, Angew. Chem., Int. Ed., 2013, 52, 3953-3957.

30 A. Mewada, S. Pandey, M. Thakur, D. Jadhav and M. Sharon, J. Mater. Chem. B, 2014, 2, 698-705.

31 V. N. Mehta, S. Jha, R. K. Singhal and S. K. Kailasa, New J. Chem., 2014, 38, 6152-6160. 
32 X. Gong, Q. Zhang, Y. Gao, S. Shuang, M. M. F. Choi and C. Dong, ACS Appl. Mater. Interfaces, 2016, 8, 11288-11297.

33 Y. Guan, Q. Tang, X. Fu, S. Yu, S. Wu and M. Chen, Food Chem., 2014, 152, 552-557.

34 D. Yu, M.-S. Chen and S.-J. Yu, Food Chem., 2016, 197, 924929.

35 Y. Guo, L. Zhang, S. Zhang, Y. Yang, X. Chen and M. Zhang, Biosens. Bioelectron., 2015, 63, 61-71.

36 Y.-L. Zhang, L. Wang, H.-C. Zhang, Y. Liu, H.-Y. Wang, Z.-H. Kang and S.-T. Lee, RSC Adv., 2013, 3, 3733-3738.
37 Z. F. Gao, T. T. Li, X. L. Xu, Y. Y. Liu, H. Q. Luo and N. B. Li, Biosens. Bioelectron., 2016, 83, 134-141.

38 J.-J. Liu, X.-L. Zhang, Z.-X. Cong, Z.-T. Chen, H.-H. Yang and G.-N. Chen, Nanoscale, 2013, 5, 1810-1815.

39 L. Yue, J. Wang, Z. Dai, Z. Hu, X. Chen, Y. Qi, X. Zheng and D. Yu, Bioconjugate Chem., 2017, 28, 400-409.

40 S. M. T. Shaikh, J. Seetharamappa, S. Ashoka and P. B. Kandagal, Dyes Pigm., 2007, 73, 211-216.

41 H. Xu, X. Yang, G. Li, C. Zhao and X. Liao, J. Agric. Food Chem., 2015, 63, 6707-6714. 